\section{$\mathbb{N} \mathbf{K I T}$}

Karlsruhe Institute of Technology
${ }^{1}$ Institute for Nuclear and Energy Technologies

${ }^{2}$ Institute of Chemical Technology and Polymer Chemistry

\title{
Interaction of heterogeneous and homogeneous kinetics with mass and heat transfer in catalytic reforming of logistic fuels
}

Lubow Maier ${ }^{1}$, Marco Hartmann², Steffen Tischer ${ }^{1}$, Olaf Deutschmann ${ }^{1,2}$

\section{Introduction}

Today, in the discussion of alternative fuels and green-house gases, devices are discussed, which use partial oxidation and steam reforming for the production of hydrogen-rich synthesis gas from conventional fuels. Two examples of such systems being currently of great technological interest are the Solid-Oxide Fuel Cell (SOFC) [1] when operated with nonpure hydrogen fuels, e.g. partially reformed logistic fuels, and short-contact time reactors for reforming gasoline and diesel fuels [2], e.g., as first stage of an on-board auxiliary power unit (APU). The non-linear coupling of complex homogeneous and heterogeneous chemical reaction kinetics with heat and mass transfer in such systems matters for reactor behavior often even superimposed by transient modifications of the active catalytic phase, e.g. by oxidation and coking

In this work, we will present a modeling and simulation study on a catalytic reformer for the production of hydrogen-rich synthesis gas from the gasoline surrogate iso-octane. This example exhibits all features mentioned above: complex homogeneous and heterogeneous reaction schemes, mass and heat transfer effects, catalyst deactivation. Present work is related to the coupling of models of these phenomena, and their computational implementation to explain the impact of residence time on fuel conversion and hydrogen production and to optimize the reactor performance.

\section{Modeling approach}

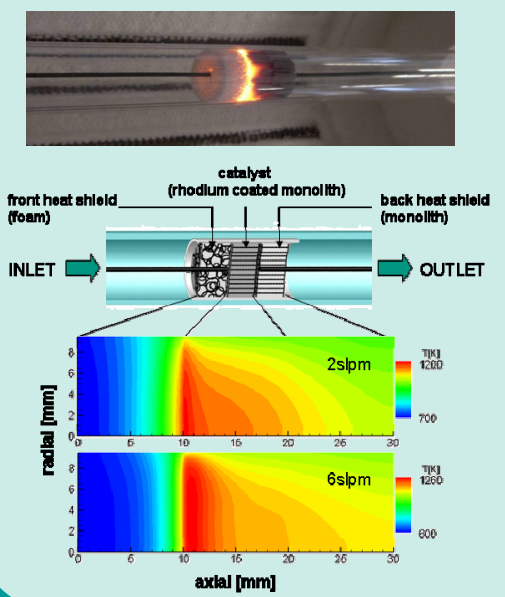

\section{Results}

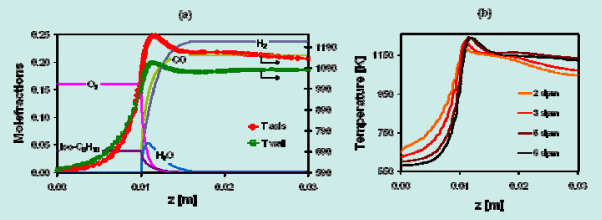

Numerically predicted axial species profiles (in the center of the single channel) in the centerline of the monolith and temperature profiles in the centerline (axis) and at the outer wall of the monoliths, $\mathrm{C} / \mathrm{O}=1.0,5 \mathrm{slpm}(\mathrm{a})$; effect of flow rate on

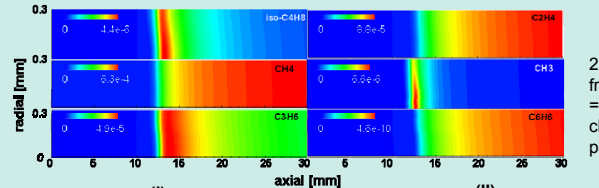

(II)
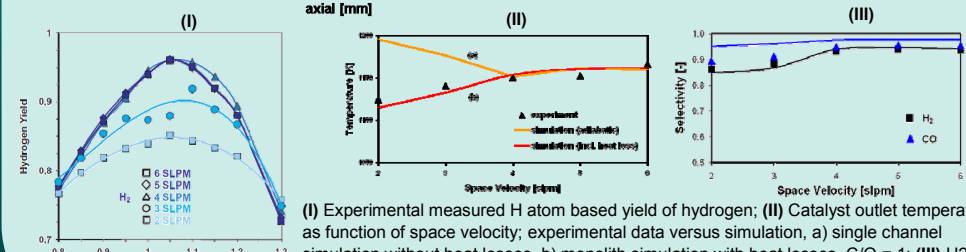

space Velocity [sipm (I) Experimental measured $\mathrm{H}$ atom based yield of hydrogen; (II) Catalyst outlet temperature as function of space velocity; experimental data versus simulation, a) single channel simulation without heat losses, b) monolith simulation with heat losses. $\mathrm{C} / \mathrm{O}=1$; (III)
$\mathrm{CO}$ selectivity as function of space velocity at $\mathrm{C} / \mathrm{O}=1$, experimental data - symbols,

POX of gasoline on rhodium (i-octane as

detailed gas phase reaction mechanism species

detailed surface reaction mechanism for $\mathrm{C} 1$ C3 surface chemistry : 111 reactions, 31

behaviour of the whole monolith (including catalyst and heat shields)

provides inlet and boundary conditions for single channel simulations

Itware DETCHEM ${ }^{\text {CHANNEL[3]: }}$

2D parabolic description of the laminar flow in the single channel of monolith catalyst models and transport phenomena

and mole of gas-phase temperature and mole 1.0 and $5 \mathrm{spm}$. The symmetry axis of the channel and the gas-wall interface are at radial ition of 0 and $0.3 \mathrm{~mm}$, respectively.

$$
\begin{aligned}
& \text { CO selectivity as func } \\
& \text { simulation-lines [5]. }
\end{aligned}
$$

\section{Experiments}

- isooctane/air mixture, $\mathrm{C} / \mathrm{O}=0.8-1.3,2-6$ SLPM

$900 \mathrm{cpsi}$ Rh coated $\left(1.41 \mathrm{mg} / \mathrm{cm}^{3}\right)$ honeycomb monolith catalyst; upstream heat shield: $85 \mathrm{ppi}$ uncoated foam $\left(\mathrm{y}-\mathrm{Al}_{2} \mathrm{O}_{3}\right)$; downstream heat shield: $600 \mathrm{cpsi}$ uncoated honeycomb

time-resolved monitoring of product species, FT-IR, MS, paramagnetic GC [4]

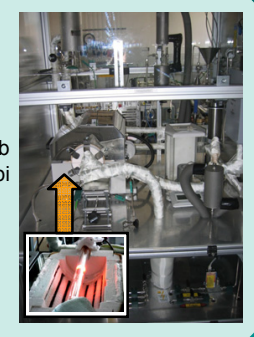

\section{Results}

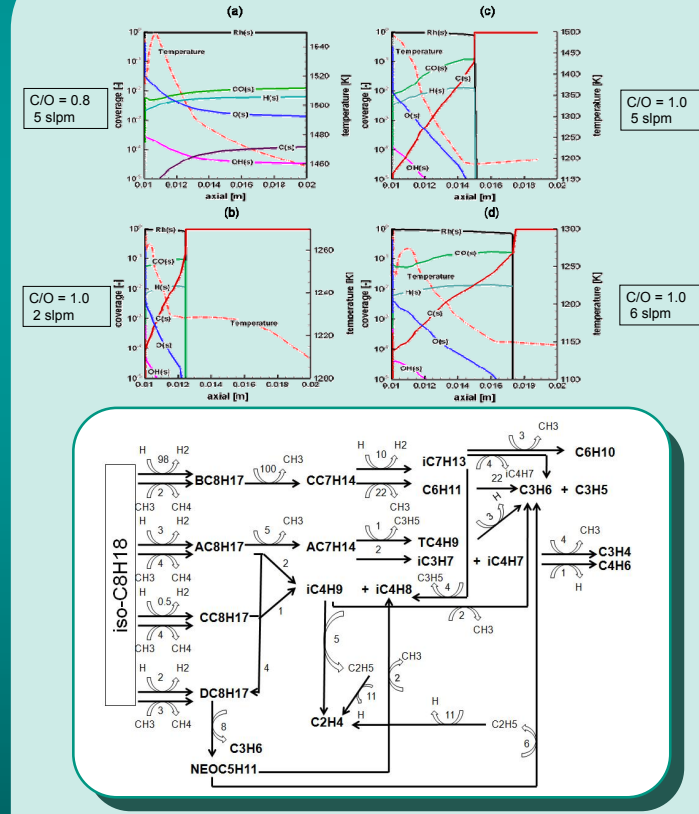

Reaction rate flow analysis for pyrolysis of iso-octane $1010 \mathrm{~K}$, residence time of $42 \mathrm{~ms}$. The time-integrated values given are scaled in a way that the maximum molar production rate of an individual reaction occurring of all reactions is set to be 100 . Note that only major paths are shown [5]. 